\title{
Tip gap size effects on thermal performance of cavity-winglet tips in transonic turbine cascade with endwall motion
}

\section{Original article}

Article history:

Accepted: 25 April 2017

Published: 27 June 2017

This paper is the updated version of a paper originally presented at the 1st Global Power and Propulsion Forum, GPPF 2017, in Zurich, Jan 16-18 2017.

\section{Check for updates}

*Correspondence:

CZ: czhou@pku.edu.cn

Peer review:

Single blind

\section{Copyright:}

(c) 2017 Zhong and Zhou. @ This is an open access article distributed under the Creative Commons Attribution License (CC-BY 4.0), which permits unrestricted use, distribution, and reproduction in any medium, provided the original work is properly cited and its authors credited.

\section{Keywords:}

thermal performance; winglet tip; transonic; endwall motion; HP turbine

\section{Citation:}

Zhong F. and Zhou C. (2017). Tip gap size effects on thermal performance of cavitywinglet tips in transonic turbine cascade with endwall motion. Journal of the Global Power and Propulsion Society. 1: 41-54. https://doi.org/10.22261/CR5JBC
Fangpan Zhong ${ }^{1}$, Chao Zhou ${ }^{2, *}$

${ }^{1}$ College of Engineering, Peking University, Beijing 100871, PR China

${ }^{2}$ State Key Laboratory for Turbulence and Complex Systems; BIC-ESAT, Peking University; Collaborative Innovation Center of Advanced AeroEngine, Beijing 100191, PR China

\begin{abstract}
The thermal performance of two cavity-winglet tips with endwall motion is investigated in a transonic high pressure turbine cascade, which operates at an engine representative exit Mach number of 1.2 and an exit Reynolds number of $1.7 \times 10^{6}$. The numerical method is first validated with experimental data and then used to investigate blade heat transfer at three different tip clearances of $1.1,2.1$ and $3.1 \%$ chord. The effects of relative endwall motion are considered. The present results show that as the size of the tip gap increases, the heat transfer coefficient and heat load on the tip increases. The winglet geometries on the blade tip mainly affect the tip flow structure close to them. At a larger tip clearance, the size of the separation bubble above the pressure side winglet increases. The heat transfer coefficient is high on the pressure side winglet due to the flow reattachment at all tip clearances. Within the tip gap, when the size of the tip clearance increases, the size of the cavity vortex increases and the cavity scraping vortex due to relative endwall motion becomes smaller. The impingement of the both two vortexes can lead to high heat transfer coefficient on the cavity floor surface. On the blade suction surface, when the size of the tip clearance increases, the heat transfer coefficient of the cavity tip increases, but those of the winglet tips decreases. The heat transfer coefficient is high on the side surface of the suction side winglet at all tip clearances because of the tip leakage flow impingement.
\end{abstract}

\section{Introduction}

In gas turbines, the tip clearance exists between the tip of turbine rotor blade and the stationary casing to prevent rubbing. The hot gas is driven across the blade tip due to the pressure difference between the blade pressure side and suction side, forming tip leakage flow. The tip leakage flow reduces the turbine efficiency and work output. According to Denton (1993), the tip leakage loss could account for one third of the total aerodynamic loss of a turbine rotor. 
Winglet tips were found to be able to reduce the tip leakage loss. A winglet refers to the extension part at the turbine tip region. It can be applied on a flat tip to form a flat-winglet tip or a squealer tip to form a squealer-winglet tip. The latter is preferred because many studies have shown that squealer tips can produce lower loss than the flat tips (Heyes et al., 1992; Key and Arts, 2006; Lee and Kim, 2010). With the additional design of winglets, the tip leakage loss of the squealer-winglet tip is believed to be lower than that of the flat-winglet tip. The aerodynamic performance of the squealer-winglet tip has been studied on both linear cascades (Zhou et al., 2013; Schabowski et al., 2014; Cheon and Lee, 2015) and rotating rigs (Harvey et al., 2006). In general, it was found that squealer-winglet tips performed better than the squealer tips.

Heat transfer is an important aspect for the tips of rotors in high pressure turbines. A review of turbine blade tip heat transfer is presented by Bunker (2001). A number of studies related to the flat tips or the squealer tips were published (e.g. Azad et al., 2000; Bunker and Bailey, 2001; Teng et al., 2001; Kwak and Han, 2003; Newton et al., 2006). Fewer studies focus on the heat transfer of the squealer-winglet tips. Papa et al. (2003) found that the squealer-winglet tip had lower average mass/heat transfer compared with the squealer tip. Saha et al. (2006) found that the pressure side winglet reduced the tip average heat transfer coefficient by $1.5 \%$ on a suction-sided squealer tip. In a transonic turbine cascade, O'Dowd et al. (2011) measured the heat transfer on winglet tip surface and near-tip side-walls of a unique squealer-winglet tip. Compared with the flat tip, they found a region of higher Nusselt number close to the tip on the suction surface. Nevertheless, the winglet tip geometries studied in different literatures are very different.

In a previous study by Zhong et al. (2017), the heat transfer performance of three different cavitywinglet tips was investigated experimentally and numerically in a transonic turbine cascade at a tip clearance of $2.1 \%$ chord. It was found that the heat transfer coefficient was very high on the pressure side winglet due to the flow separation reattachment and also quite high on the side surface of the suction side winglet due to the impingement of the tip leakage vortex. Their results also showed that the effect of endwall motion between the blade tip and casing was significant, which was also observed by other researchers, such as Yaras and Sjolander (1992), Tallman and Lakshminarayana (2001), Rhee and Cho (2006), Palafox et al. (2012) and Zhou (2015).

For a turbine, the size of the tip clearance varies and this effect changes the thermal performance of the tips. This paper presents a following work of Zhong et al. (2017). The aim is to understand the effect of tip clearance on the thermal performance of different winglet tips with endwall motion. In this study, two winglet tips and a baseline cavity tip are investigated at three tip clearances of 1.1, 2.1 and $3.1 \%$ chord. The heat transfer on the tip and near tip surface are presented and the flow field is analysed to give explanations to the thermal performance of the blade tips.

\section{Computational details}

\section{Tip geometry}

The tip geometries are shown in Figure 1. They are the same as those used in the previous study by Zhong et al. (2017). The width and height of the cavity squealer are 2.6 and $5.1 \%$ chord respectively. The winglet tip "SSW" has a suction side fore-part winglet between $0.15 C x$ and $0.62 C_{x}$. The winglet tip "PSW" has the same suction side winglet as "SSW" and a pressure side winglet. The design of the suction side winglet is based on the method proposed by Zhou and Zhong (2016). The cascade profile is the blade geometry near the tip of a modern transonic high pressure turbine rotor. The main parameters of the cascade are listed in Table 1.

\section{Meshing and computational solver}

Figure 2 shows the computational domain and mesh of the cavity tip. The computational domain uses one blade with periodic boundary conditions to simulate a row of blades. The inlet of the 


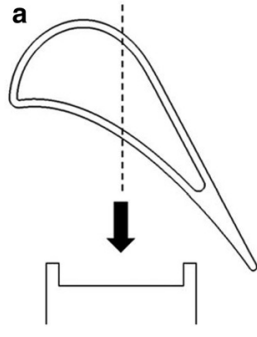

Cavity

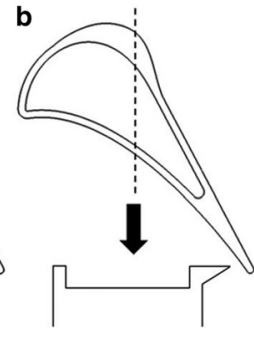

SSW

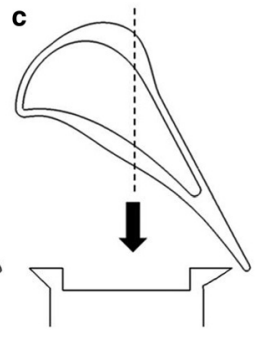

PSW

Figure 1. Tip geometries. which are discretized in space using a second order. The turbulence model is Spalart-Allmaras model. The "pressure inlet" and "pressure outlet" conditions are applied to the inlet and outlet of the computational domain. For each case, the inlet flow parameters are all uniform. The inlet turbulence intensity is $10 \%$. The "hub" is set as "symmetry" condition. The "casing" is set as a moving wall to simulate the relative motion between the blade tip and the casing, because it was found that effects of the centrifugal force and the Coriolis force were much smaller than the effect relative endwall motion (Yang et al., 2010; Acharya and Moreaux, 2013). The flow coefficient is 0.4 . The cascade exit Mach number is 1.2 and the exit Reynolds number (based on chord) is $1.7 \times 10^{6}$.

The blade surface heat transfer coefficient (HTC) is obtained based on the results of two calculations. One with blade surface set as adiabatic wall and the other with blade surface set as isothermal wall with wall temperature of $T_{w}$. HTC is defined as follows:

$$
H T C=\frac{q}{T_{a d}-T_{w}}
$$

where $q$ is the local heat flux obtained in the calculation with isothermal wall temperature of $T_{w}, T_{a d}$ is the adiabatic wall temperature obtained in the calculation with adiabatic wall condition. In the current study, $T_{w}$ is $197 \mathrm{~K}$, which gives an engine representative gas to wall temperature ratio of 1.5 .

The mesh sensitivity study is conducted on the winglet tip "PSW" at a tip clearance of $2.1 \% C$. Three different mesh quantities of 6.5, 8.5 and 10 million are used. The mesh was refined in the spanwise direction. The tip average $\mathrm{y}^{+}$and average heat transfer coefficient are listed in Table 2. The tip average $H T C$ decreases by 1.8 and $1.9 \%$ when the mesh quantity increases from 6.5 to 8.4 million and 10 million.

\section{Experimental validation}

Figure 3 shows the experimental and predicted tip HTC of the winglet tip "PSW" without endwall motion at two tip clearances of $1.1 \% C$ and $2.1 \% C$ for validation. The details of the experiment and the result analysis for tip clearance of $2.1 \% C$ have been reported by Zhong et al. (2017). The HTC is obtained by the same method used by Ma et al. (2016). The experimental uncer-

Table 1. Main parameters of the cascade.

\begin{tabular}{|l|c|}
\hline Blade Inlet Angle $\left(\beta_{1}\right)$ & $45.0^{\circ}$ \\
\hline Blade Exit Angle $\left(\beta_{2}\right)$ & $-57.0^{\circ}$ \\
\hline Chord $(C)$ & $46.8 \mathrm{~mm}$ \\
\hline Axial Chord $\left(C_{x}\right)$ & $39.2 \mathrm{~mm}$ \\
\hline Span $(H)$ & $43.0 \mathrm{~mm}$ \\
\hline Pitch $(t)$ & $37.9 \mathrm{~mm}$ \\
\hline
\end{tabular}
tainty of the tip area-weighted averaged $H T C$ is $\pm 9.4 \%$. The HTC is quite high on the pressure side winglet surface. As the tip clearance increases, the $H T C$ on the cavity floor surface and on the suction side winglet surface increases, while the $H T C$ on the pressure side winglet surface decreases. The Computational Fluid Dynamics (CFD) well predicts these trends.

Figure 4 presents the $H T C$ distribution at two axial locations of $0.5 C_{x}$ and $0.9 C_{x}$ as indicated in Figure 3b. In Figure 4a, both the CFD and 


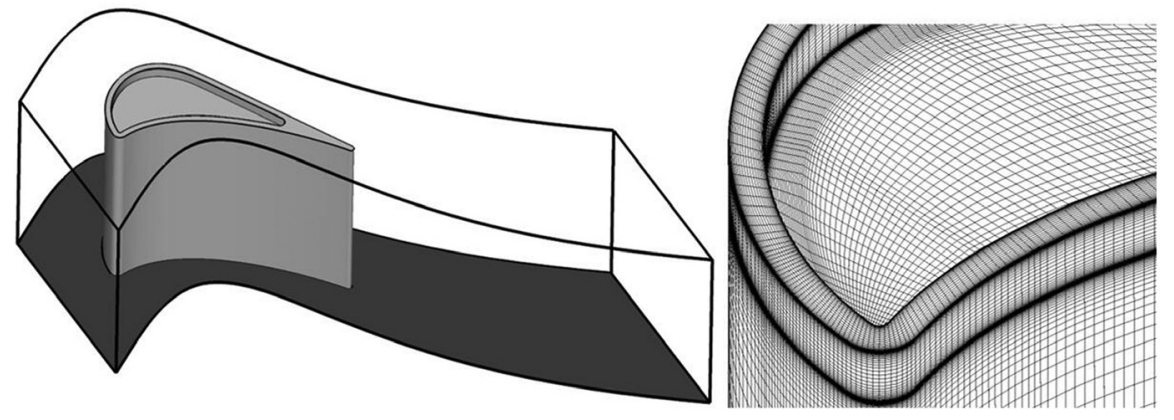

Figure 2. Computational domain and mesh of the cavity tip.

Table 2. Mesh sensitivity study of winglet tip "PSW" at tip clearance of $2.1 \%$.

\begin{tabular}{|l|c|c|c|}
\hline & Mesh 1 & Mesh 2 & Mesh 3 \\
\hline Mesh quantity (million) & 6.5 & 8.4 & 10 \\
\hline Tip average ${ }^{+}$ & 2.1 & 1.3 & 1.2 \\
\hline Tip average HTC $\left(\mathrm{W} / \mathrm{m}^{2} \cdot \mathrm{K}\right)$ & 1213.1 & 1191.7 & 1189.7 \\
\hline
\end{tabular}

experiment show that the $H T C$ is relatively low inside the cavity. The CFD under predicts the $H T C$ value on the pressure side winglet and inside the cavity, but agrees well with the experiment on the suction side winglet. In Figure 4b, the CFD result shows that HTC decreases as tip clearance increases. However, the experimental result shows that the HTC decreases on the pressure side but increases on the suction side. Note that at the two locations, the discrepancy is large near the blade tip edge and squealer corner. One possible reason is that the blade tip edge radius is not considered in the calculation, so the flow separation above the squealer/winglet can not be modelled accurately. Another reason is that the three-dimentional conduction effect is ignored in the experimental data processing.

Figure 5 shows the relative $H T C$ difference between the numerical and experimental results. Inside the

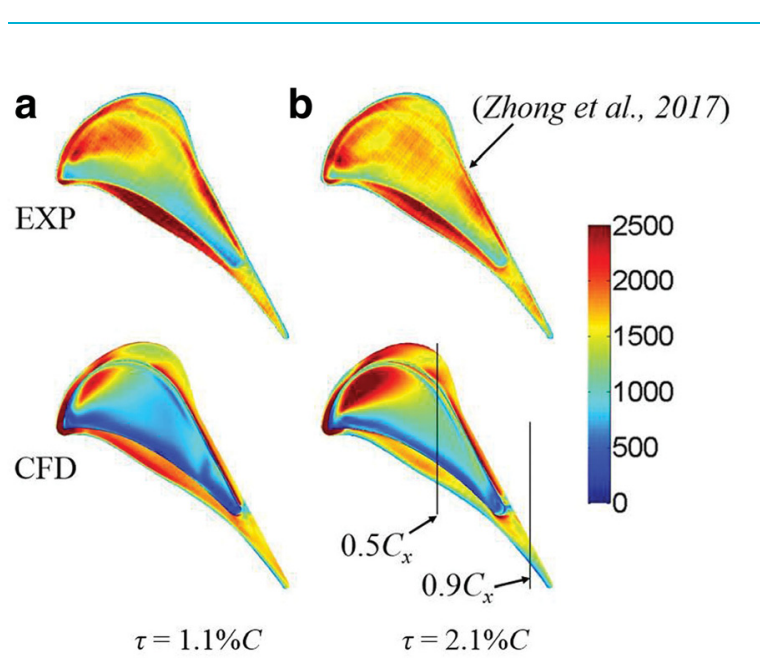

Figure 3. Experimental and predicted tip heat transfer coefficient of winglet tip "PSW" without endwall motion. cavity, the CFD under predicts the HTC in most areas except for region "A." The biggest difference occurs in region " $B$ " near the pressure side winglet, where the CFD under predicts the $H T C$ by 50 to $75 \%$. On the pressure side, suction side winglet surfaces and near the trailing edge region, the relative difference is mainly within $\pm 20 \%$ except for region " $C$ " and the blade tip edge.

\section{Results and Discussion}

The results presented in this part are obtained by numerical methods with relative endwall motion. Besides, all the flow field results are obtained based on the simulations with the "blade" and "casing" set as the adiabatic wall. 


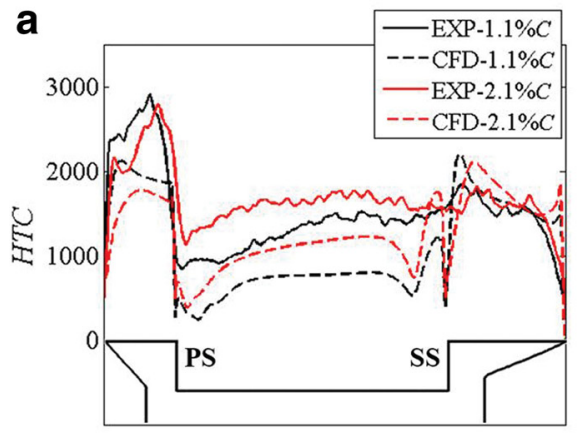

$0.5 C_{x}$

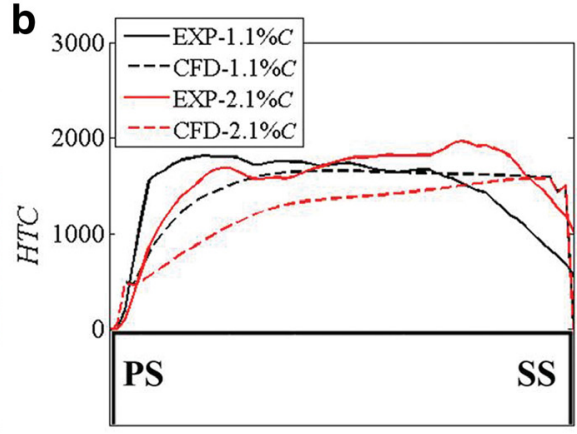

$0.9 C_{x}$

Figure 4. Comparison of heat transfer coefficient at two axial locations of (a) $0.5 C x$ and (b) $0.9 C x$.

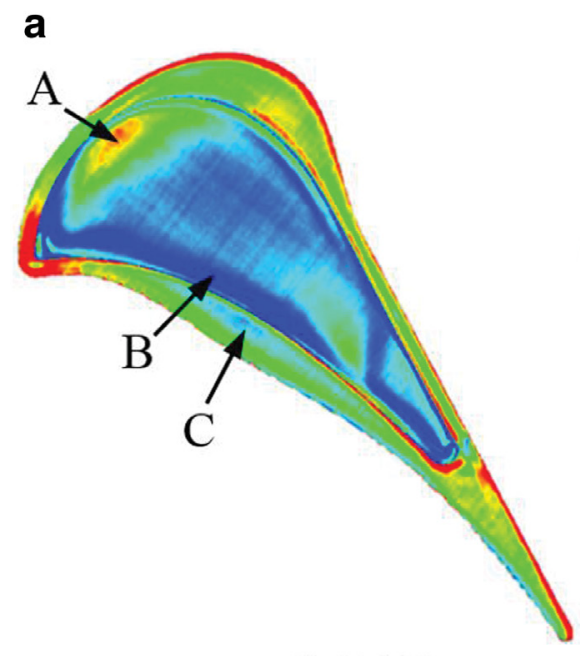

$\tau=1.1 \% C$ b

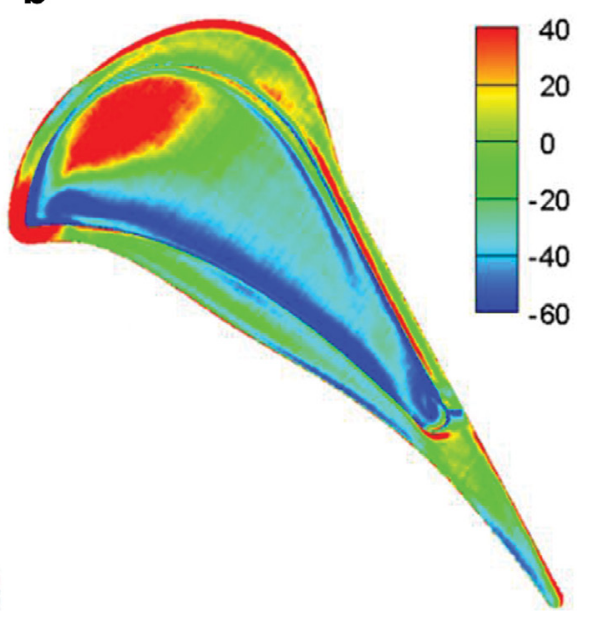

$\tau=2.1 \% C$

Figure 5. Relative difference of tip heat transfer coefficient of winglet tip "PSW" without endwall motion (in percent).

\section{Tip heat transfer results}

Figure 6 shows the distribution of tip heat transfer coefficient of different tip geometries with endwall motion. For the cavity tip, as the tip clearance increases, the HTC on the cavity floor surface generally increases. The area of high $H T C$ region " $A$ " and " $\mathrm{C}$ " becomes bigger while the area of low HTC region "B" becomes smaller. The HTC above the pressure side squealer decreases with the tip clearance.

Compared with the cavity tip, the suction side winglet has little effect on the HTC distribution above the pressure side squealer and on the cavity floor surface at all tip clearances. The pressure side winglet slightly reduces the $H T C$ on the cavity floor, but the distribution pattern is very similar with that of the cavity tip. The $H T C$ on the pressure side winglet is much higher than that on the suction side winglet. As the size of the tip gap increases from $1.1 \% C$ to $3.1 \% C$, the $H T C$ on the pressure side winglet first increases and then decreases. The winglets mainly change the flow structure locally above the winglet geometries, and the HTC distribution on the suction side winglet of "SSW" and "PSW" is very similar. So, the tip flow structure of winglet tip "PSW" will be presented to explain the tip heat transfer results. 


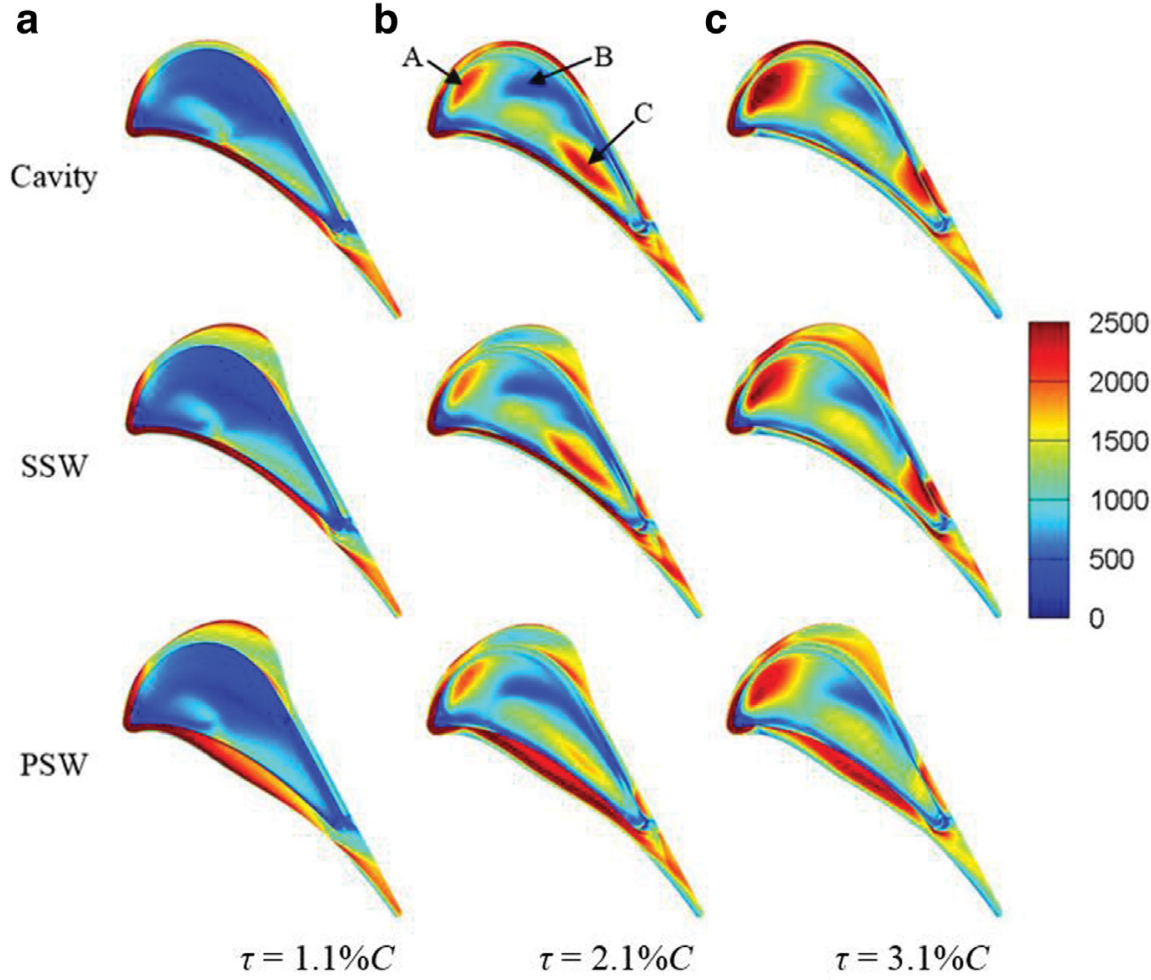

Figure 6. Tip HTC distribution of all tips.

Figure 7 shows the HTC distribution on inner vertical squealer surface of winglet tip "PSW." The results of cavity tip and winglet tip "SSW" are not presented because they are quite similar with the result of "PSW." At the smallest tip clearance, the $H T C$ is less than $1000 \mathrm{~W} / \mathrm{m}^{2} \cdot \mathrm{K}$ in most areas. A local high-HTC spot appears in region "A" on the pressure side and the maximum HTC value is about $2900 \mathrm{~W} / \mathrm{m}^{2} \cdot \mathrm{K}$. As the tip clearance increases, the $H T C$ increases because the flow velocity inside the cavity near the vertical squealer increases with the tip clearance as shown in Figure 10 and Figure 11. At tip clearances of $2.1 \% C$ and $3.1 \% C$, the $H T C$ in region "B" and " $\mathrm{C}$ " is relatively larger. The maximum value in region " $\mathrm{B}$ " is $2300 \mathrm{~W} / \mathrm{m}^{2} \cdot \mathrm{K}$ and $2900 \mathrm{~W} / \mathrm{m}^{2} \cdot \mathrm{K}$ for $\tau=$ $2.1 \% C$ and $\tau=3.1 \% C$ respectively, while it is about $4600 \mathrm{~W} / \mathrm{m}^{2} \cdot \mathrm{K}$ in region " $\mathrm{C}$ " for the two tip clearances.

Figure 8 shows the Mach number distributions and two-dimensional streamlines on the cut plane in the middle of the tip gaps of winglet tip "PSW." The dark contour lines correspond to Ma $=1$. The flow enters the tip gap from the pressure side and front part of the suction side region. At all tip clearances, the subsonic flow dominates the region inside the tip gap except for the region above the suction side squealer after the middle chord, where the flow becomes supersonic. The flow inside the tip gap is deflected due to the shear force caused by the endwall motion. The flow is deflected more towards the tangential direction at a smaller tip gap. The Mach number of the flow within the tip cavity generally increases with the tip clearance.

Figure 9 shows the 3D tip flow streamlines of winglet tip "PSW" coloured by flow Mach number at three tip clearances. Near the leading edge, the flow enters the tip gap and impinges on the cavity floor surface, which results in the high HTC region "A" shown in Figure 6b. Then the flow rolls up to form the "Leading Edge Vortex"(LEV). Above the pressure side winglet, the flow first separates and then reattaches on the winglet surface, which results in local high HTC as shown in Figure 6. The height and length of the separation zone increases as the tip clearance increases. Inside the cavity, the flow entering from the pressure side rolls up to form the "Cavity Vortex" $(\mathrm{CV})$, the size of which increases as the tip clearance increases. It is interesting to find that at the smallest tip clearance, the CV seems to be 


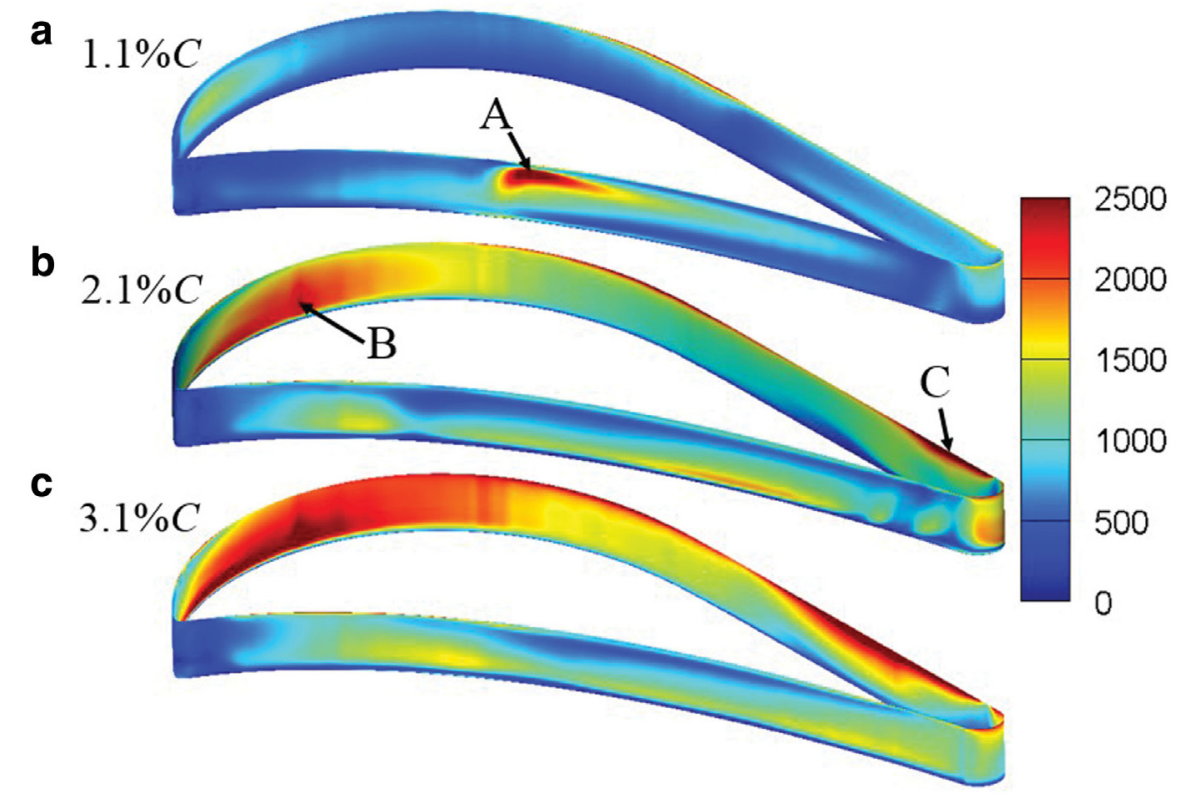

Figure 7. HTC distribution on inner vertical squealer surface of winglet tip "PSW."

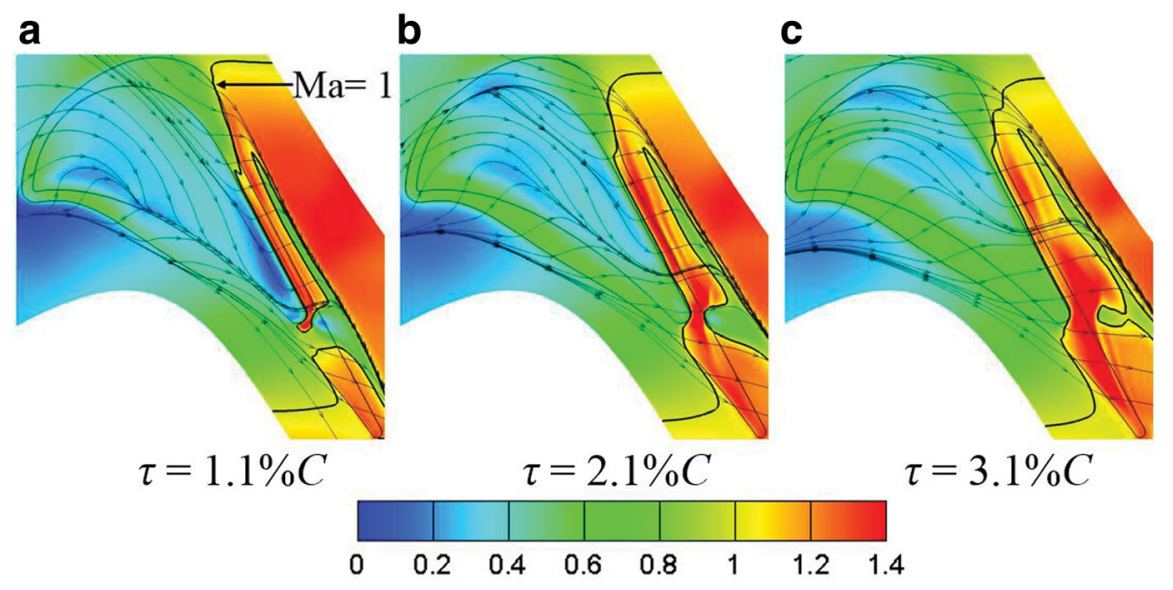

Figure 8. Mach number on the middle plane of the tip gap of winglet tip "PSW."
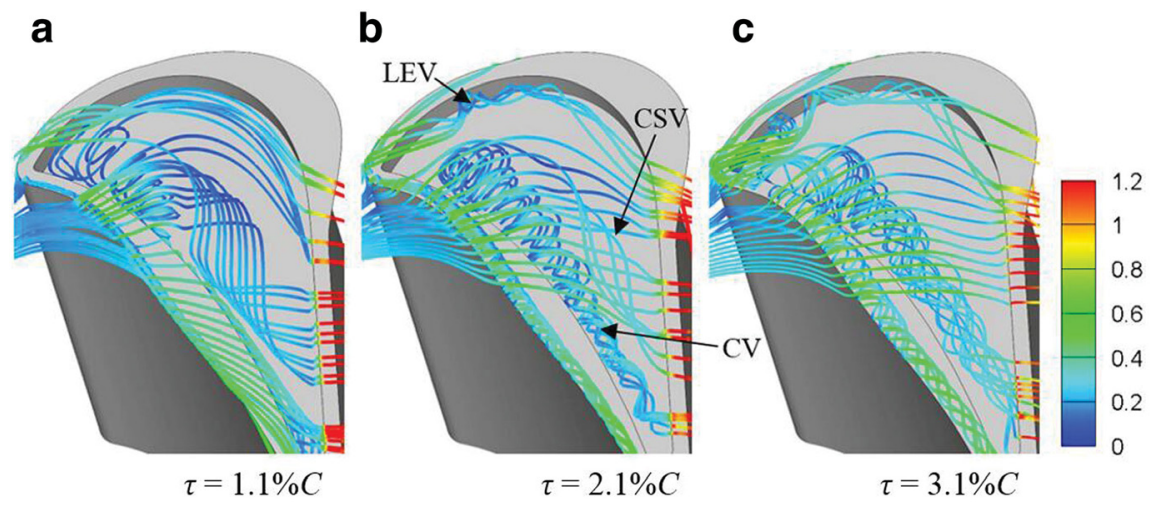

Figure 9. Tip flow streamlines of winglet tip "PSW." 


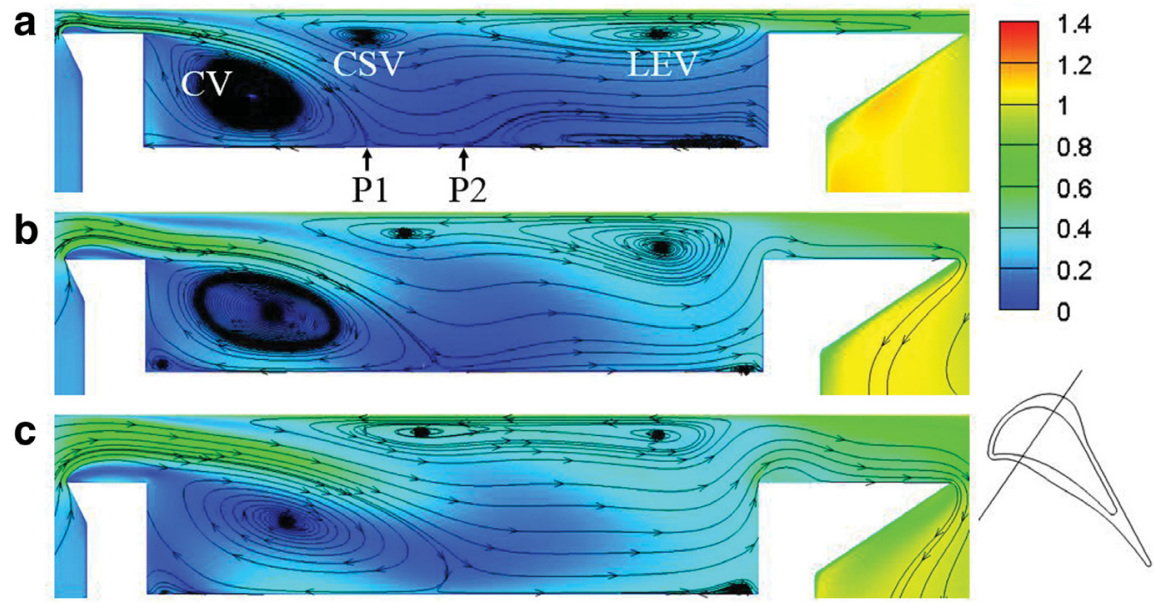

Figure 10. Mach number distribution on the cross section plane in the blade frontal region of winglet tip "PSW": (a) $1.1 \% \mathrm{C}$, (b) $2.1 \% \mathrm{C}$, and (c) $3.1 \% \mathrm{C}$.

divided into two parts: the part near leading edge has a relatively larger size while the other is smaller and is confined to the pressure side squealer corner. It is the impingement of the $\mathrm{CV}$ that leads to the high $H T C$ region "B" shown in Figure 6b. The flow near the casing is strongly affected by the endwall motion and it rolls up to form the "Cavity Scraping Vortex"(CSV). On the contrary to the "CV," the size of this vortex reduces as the tip clearance increases, which will be further discussed later.

Figure 10 shows the Mach number contours along with two-dimensional streamlines on a cross section plane in the frontal blade passage of winglet tip "PSW." As the tip clearance increases, the size of both the separation bubble above the pressure side winglet and suction side winglet becomes larger. Note that the flow hardly reattaches on the top of the pressure side winglet at the largest tip clearance. Above the cavity floor, the structures of the CV, the CSV and the LEV can be identified clearly. In Figure 10a, "P1"

a

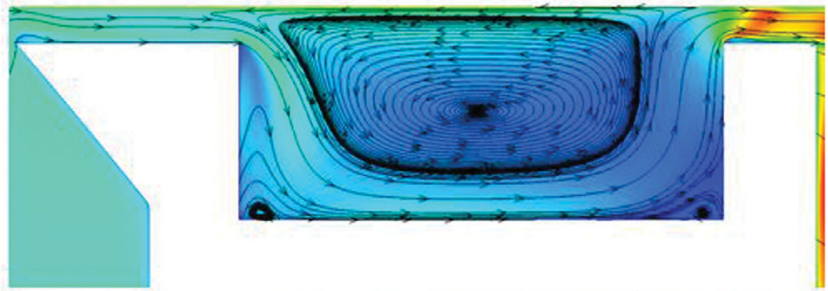

b

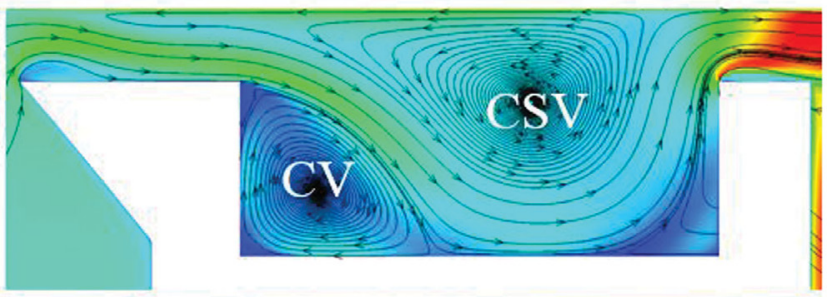

C
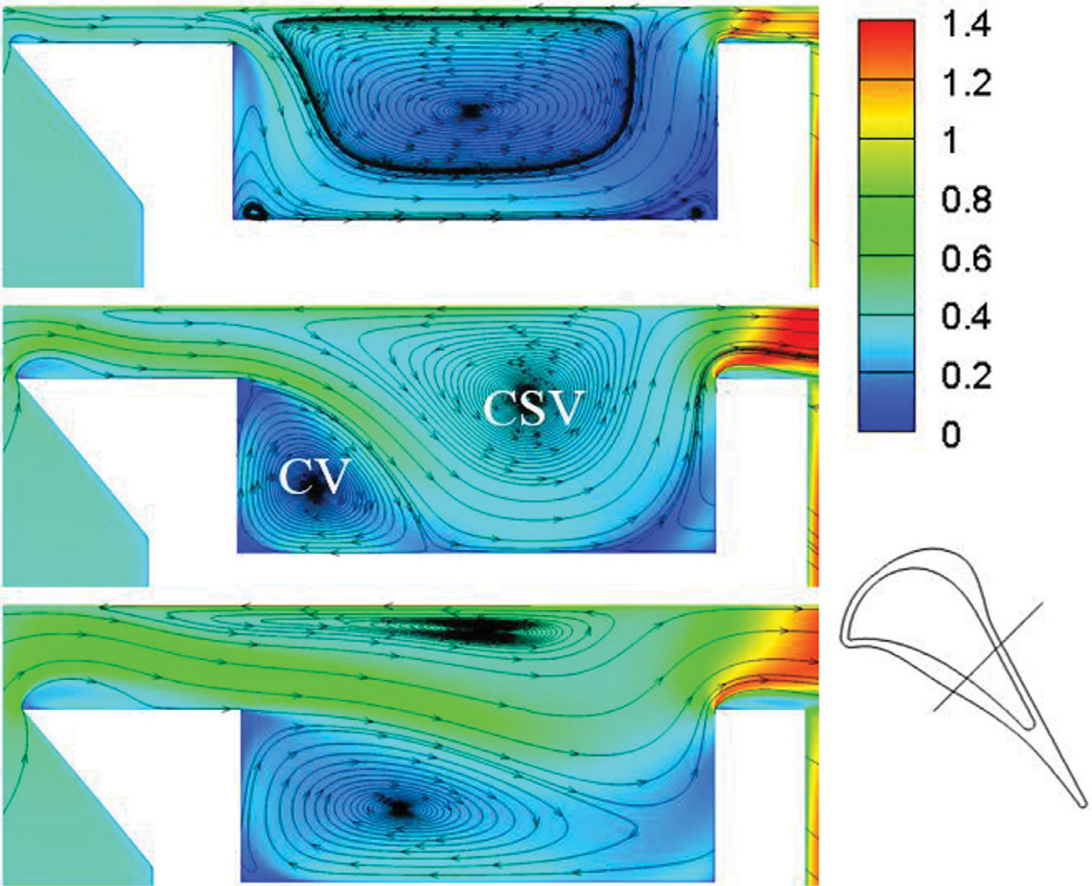

Figure 11. Mach number on the cross section plane in the blade rear part region of winglet tip "PSW": (a) $1.1 \% C$, (b) $2.1 \% C$, and (c) $3.1 \% C$. 
indicates the impingement singularity point, and "P2" indicates the separation singularity point, at which the flow begins an upward motion and results in very low HTC in region "B" shown in Figure 6b.

Figure 11 shows the Mach number contours along with two-dimensional streamlines on a cross section plane in the rear blade passage of winglet tip "PSW." As tip clearance increases, the size of CV increases and the size of the CSV decreases. The CSV impinges on the cavity floor surface at tip clearance of $1.1 \% C$ and $2.1 \% C$, causing high- $H T C$ region " $C$ " in Figure $6 \mathrm{~b}$. At the smallest tip clearance of $1.1 \%$ $C$, the size of the CV on this plane is much smaller than that shown in Figure 10a, which is consistent with that observed in Figure 9a.

Figure 12 shows the wall shear stress and the limit streamline on the cavity floor surface of winglet tip "PSW." The distribution pattern of the wall shear stress is consistent with the HTC distribution pattern shown in Figure 6. The red dashed line indicates the impingement singularity ("P1" in Figure 10a) and the white dashed line indicates the separation singularity ("P2" in Figure 10a). With a larger tip clearance, the wall shear stress near the blade leading edge is bigger, which reveals a stronger impingement effect in this region and hence higher HTC. At $\tau=3.1 \% C$, the high- $H T C$ region "C" shown in Figure 6b is located below the red dashed line, which indicates that the high $H T C$ here is mainly caused by the impingement of the CV. However, for tip clearance of $1.1 \% C$ and $2.1 \% C$, part of the high HTC region "C" is located above the red dashed line, indicating that CSV is partly responsible for the high $H T C$ on the cavity floor. This has been proven by Figure 11, which shows that the CSV is very close to the cavity floor surface and the impingement effect is significant at these two tip clearances. The white dashed line in the low wall shear stress region shows that the low HTC on the cavity floor is mainly caused by the flow upward motion induced by the CSV.

Figure 13 shows the area-weighted average $H T C$ on the blade tip of all tips. In general, the average $H T C$ increases with the tip clearance. At the smallest tip clearance of $1.1 \% C$, the difference between the average $H T C$ of all tips is negligible. Compared with the cavity tip, the winglet tip "SSW" reduces the average $H T C$ by $2.2 \%$ and $1.7 \%$ for $\tau=2.1 \% C$ and $\tau=3.1 \% C$ respectively, and the corresponding decrement of winglet tip "PSW" is 3.7 and $6.7 \%$.

The heat load $Q$ is another important parameter for heat transfer study. It is defined as follows:

$$
Q=\int_{A} q d A
$$

where $q$ is the local heat flux in the small area $d A$. For a blade tip, a higher heat load requires a larger mass of the coolant flow, which may reduce the engine performance. Figure 14 shows the total heat load on the tip surface at three tip clearances. The heat load is normalized by the total tip heat load of cavity tip at the smallest tip clearance of $1.1 \% C$. For all tips, the total tip heat load increases with the tip clearance. The winglet tip "PSW" has the largest heat load because it has the largest tip surface area. At the largest tip clearance, the heat load of winglet tip "PSW" and "SSW" is nearly the same.
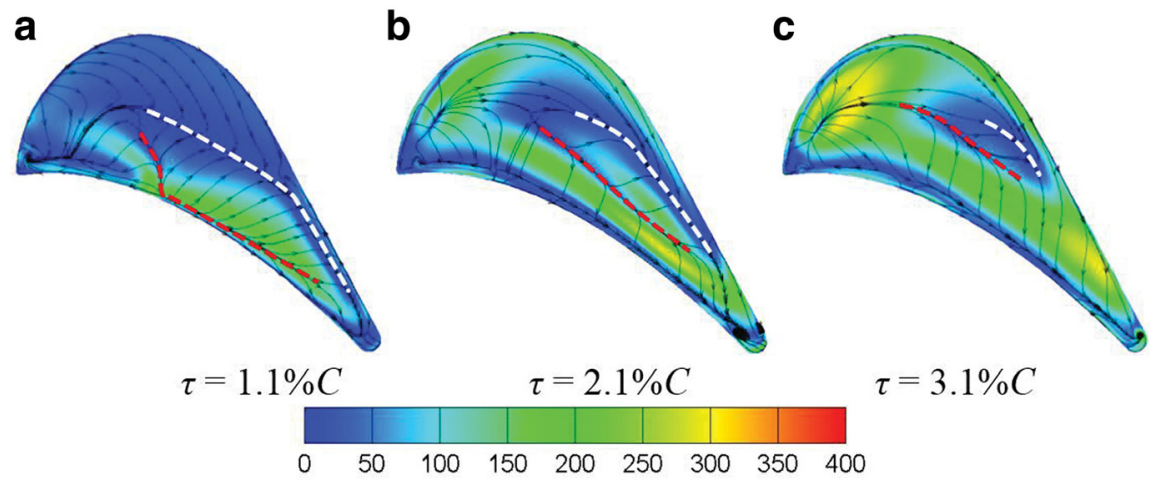

Figure 12. Wall shear stress and limit streamline on cavity floor surface of winglet tip "PSW." 


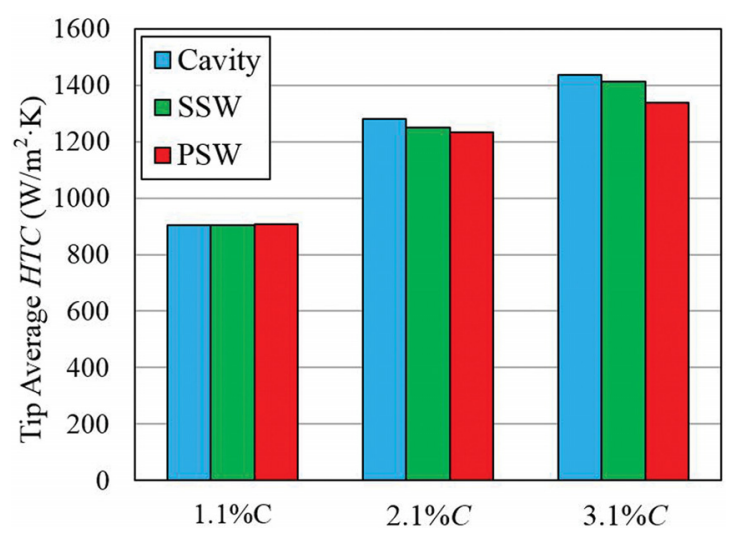

Figure 13. Tip average HTC of all tips at three tip clearances.

\section{Blade suction side heat transfer results}

Figure 15 shows the HTC distribution on the blade suction side surface for all tips at different tip clearances. A high-HTC strip (indicated by "A" in Figure 15a) appears near the tip region. Specifically, the $H T C$ is quite high on the side surface of the suction side winglet (indicated by " $\mathrm{B}$ " in Figure 15a).

Figure 16 shows the total pressure loss coefficient and velocity vector on the same plane as Figure 10 of cavity tip and winglet tip "SSW." For both tips, after the tip leakage flow discharges from the tip gap, it interacts with the main flow and rolls up to form the tip leakage vortex. The flow deflects its direction and has an impingement effect on the side surface of the blade, which causes the high HTC in area "B" shown in Figure 15. There is little difference between the HTC distributions of the two winglet tips, as the pressure side winglet has little effect on the tip leakage vortex structure. The interesting thing is that the HTC in region "A" generally increases with the tip clearance for the cavity tip, but it decreases with tip clearance for the two winglet tips. Why is this the case?

Figure 17 shows the total pressure loss coefficient on a cut plane normal to blade suction side edge of cavity tip and winglet tip "SSW." For both tips, the size of tip leakage vortex increases as the tip clearance increases. For the cavity tip, the tip leakage vortex attaches on the blade surface and the distance between the vortex core and the blade wall changes little at all tip clearances. So the HTC on the blade wall increases mainly because more fluid impinges on the wall at a larger tip clearance. However, for winglet tip "SSW," the tip leakage vortex becomes further away from the blade wall as the tip clearance increases, which reduces the impingement effect of the vortex. This is why the HTC

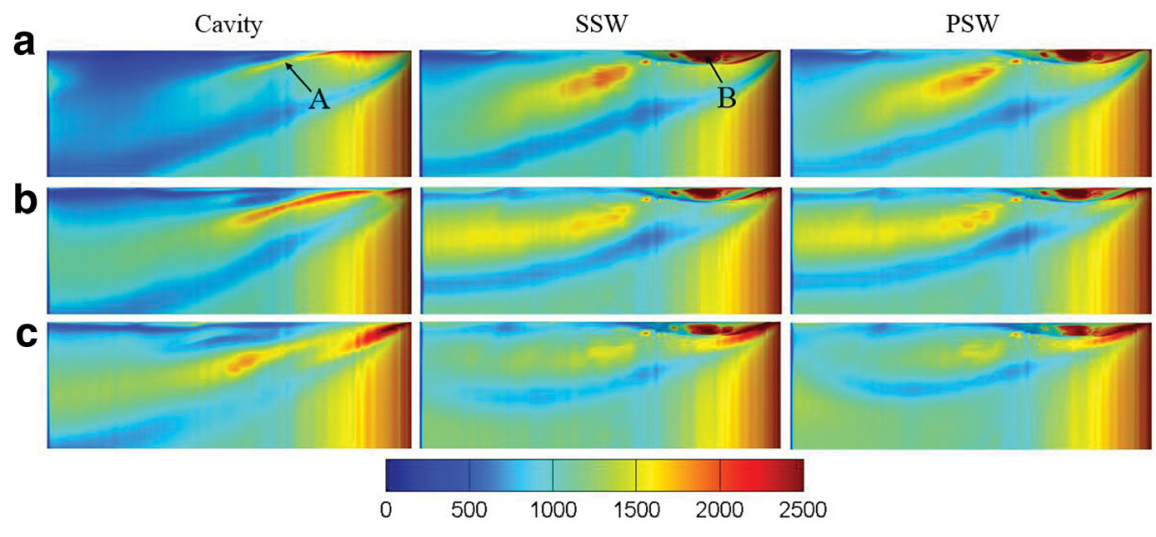

Figure 15. HTC distribution on blade suction side surface: (a) $1.1 \% C$, (b) $2.1 \% C$, and (c) $3.1 \%$. 
a

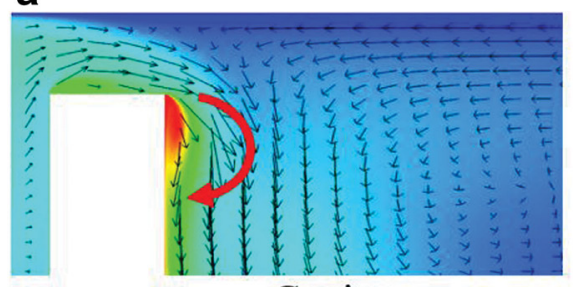

Cavity b

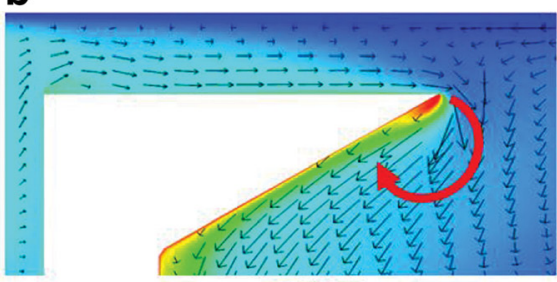

SSW

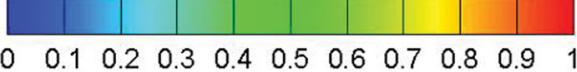

Figure 16. Total pressure loss coefficient and velocity vector on the same plane as shown in Figure 10 of cavity tip and winglet tip "SSW."

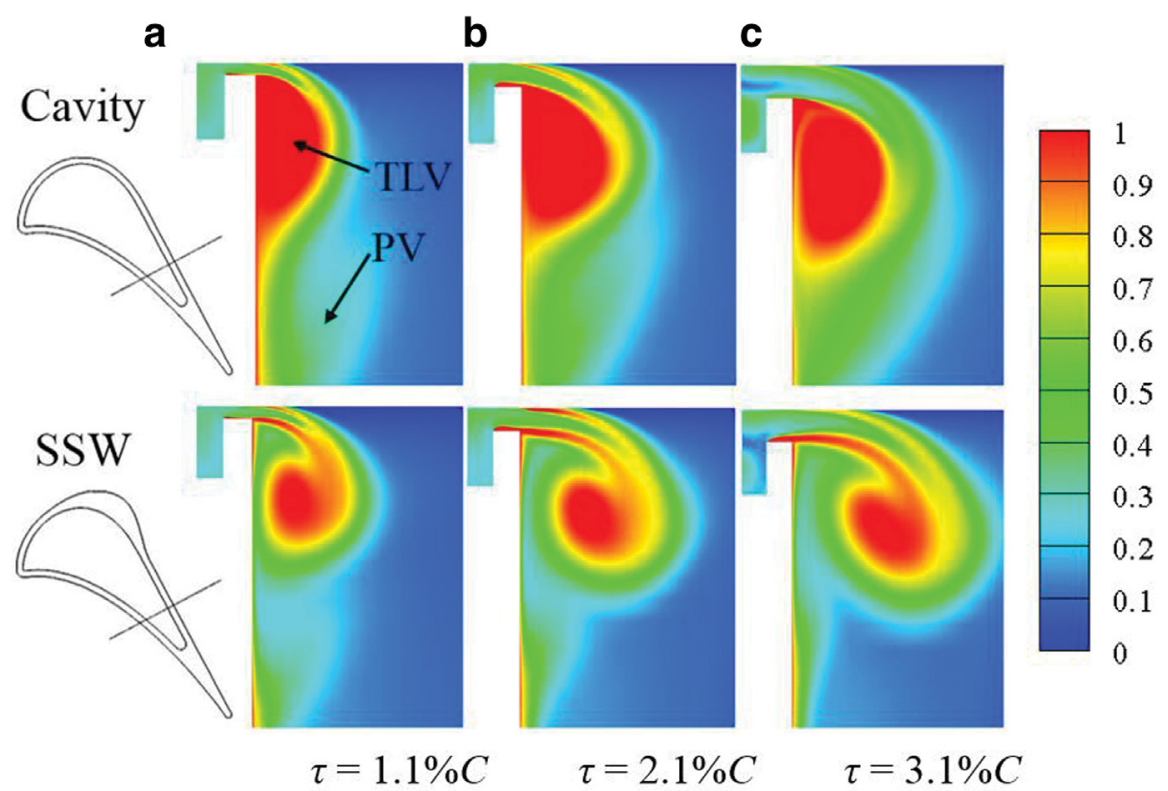

Figure 17. Total pressure loss coefficient on a cut plane normal to blade suction side of cavity tip and winglet tip "SSW."

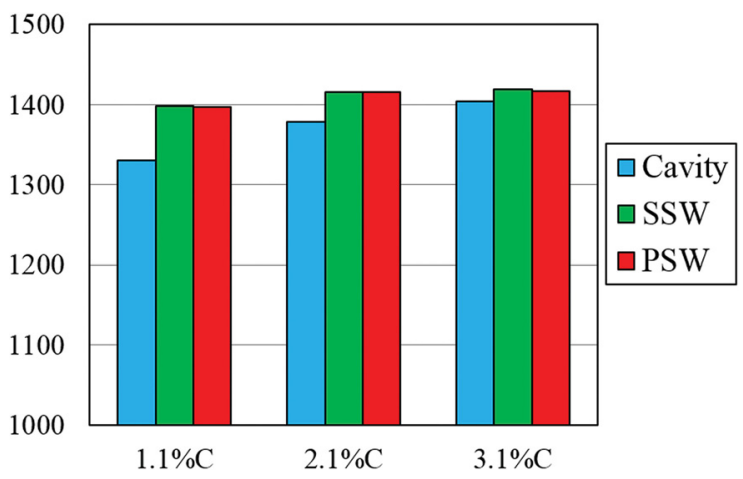

Figure 18. Average HTC on blade suction side surface of all tips at three tip clearances. on the blade wall decreases with the tip clearance. In addition, it is very interesting to find that the total pressure loss coefficient in the tip leakage vortex region is reduced by such a small suction side winglet, and the passage vortex is also suppressed at all tip clearances.

Figure 18 shows the area-weighted average HTC on the blade suction side surface of all tips. The average HTC of the cavity tip increases with the tip clearance and is the lowest at all tip clearances. There is little difference between the two winglet tips, indicating that the pressure side winglet has little effect on the tip leakage vortex structure 
in this study. Compared with the cavity tip, the two winglets increase the average HTC by 5.0, 2.7 and $0.9 \%$ at tip clearance of $1.1 \% C, 2.1 \% C$ and $3.1 \% C$ respectively.

\section{Conclusions}

This paper investigates the thermal performance of two cavity-winglet tips with endwall motion under transonic conditions at three tip clearances of 1.1, 2.1 and 3.1\% chord. The conclusions can be drawn as follows:

1. The effects of tip gap size on the thermal performance of cavity-winglet tips are significant. The average tip HTC and total tip heat load increase as the size of the tip gap increases.

2. The $H T C$ on inner vertical squealer surface generally increases with the tip clearance because the flow velocity inside the cavity near the vertical squealer increases with the tip clearance.

3. With a pressure side winglet, the tip leakage flow reattaches on the top surface of the winglet after the separation from the pressure side edge, which results in high HTC. The size of the separation bubble over the pressure side winglet increases with the tip clearance.

4. Inside the cavity, as the tip clearance increases, the size of the CV increases, resulting in higher heat transfer. The CSV becomes smaller and lifts off from the cavity floor surface, which reduces the area of the low $H T C$ region on the cavity floor. The CSV also increases the HTC on the cavity floor at tip clearance of $1.1 \% C$ and $2.1 \% C$ because it is very close to the floor surface and its impingement effect is evident.

5. The HTC in the near-tip region on the blade suction side wall of the two winglet tips decreases with the tip clearance, showing opposite trend to that of the cavity tip. This is because the tip leakage vortex of the two winglet tips locates further away from the blade wall as the tip clearance increases, reducing the impingement effect of the tip leakage vortex.

6. The $H T C$ is high on the side surface of the suction side winglet at all tip clearances because of the tip leakage flow impingement.

\section{Nomenclature}

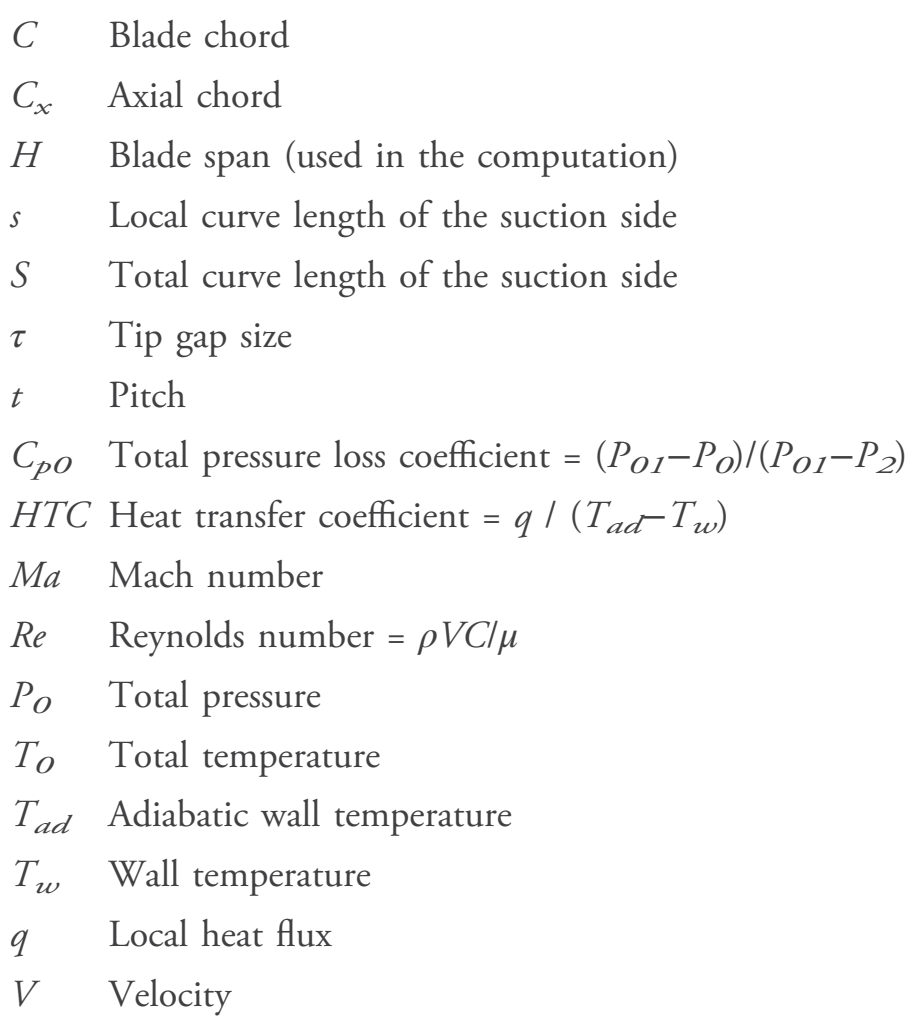



$\rho \quad$ Density
$\mu \quad$ Dynamic viscosity
$\phi \quad$ Flow coefficient

\section{Subscripts}

1 Cascade inlet

2 Cascade exit

\section{Funding sources}

The authors would like to acknowledge the support of the National Natural Science Foundation of China (NSFC), Grant No.51576003.

\section{Competing interests}

Fangpan Zhong declares that he has no conflict of interest. Chao Zhou declares that he has no conflict of interest.

\section{References}

Acharya S. and Moreaux L. (2013). Numerical study of the flow past a turbine blade tip: Effect of relative motion between blade and shroud. ASME Journal of Turbomachinery. 136 (3): 031015. https://doi.org/10.1115/1.4024842.

Azad G. S., Han J., and Boyle R. J. (2000). Heat transfer and flow on the squealer tip of a gas turbine blade. ASME Journal of Turbomachinery. 122 (4): 725-732. https://doi.org/10.1115/1.1311284.

Bunker R. S. (2001). A review of turbine blade tip heat transfer in gas turbine systems. Annals of the New York Academy of Sciences. 934 (1): 64-79. https://doi.org/10.1111/j.1749-6632.2001.tb05843.x.

Bunker R. S. and Bailey J. C. (2001). Effect of squealer cavity depth and oxidation on turbine blade tip heat transfer. ASME Paper No. 2001-GT-0155. https://doi.org/10.1115/2001-GT-0155.

Cheon J. H. and Lee S. W. (2015). Tip leakage aerodynamics over the cavity squealer tip equipped with full coverage winglets in a turbine cascade. International Journal of Heat and Fluid Flow. 56: 60-70. https://doi.org/ 10.1016/j.ijheatfluidflow.2015.07.003.

Denton J. D. (1993). Loss mechanisms in turbomachines. ASME Paper No. 93-GT-435. https://doi.org/10.1115/93-GT435.

Harvey N., Newman D., and Haselbach F. (2006). An investigation into a novel turbine rotor winglet: Part 1 — design and model rig test results. ASME Paper No. GT2006-90456. https://doi.org/10.1115/GT2006-90456.

Heyes F. J. G., Hodson H. P., and Dailey G. M. (1992). The effect of blade tip geometry on the tip leakage flow in axial turbine cascades. ASME Journal of Turbomachinery. 114 (3): 643-651. https://doi.org/10.1115/1.2929188.

Key N. L. and Arts T. (2006). Comparison of turbine tip leakage flow for flat tip and squealer tip geometries at high speed conditions. ASME Journal of Turbomachinery. 128 (2): 213-220. https://doi.org/10.1115/1.2162183.

Kwak J. S. and Han J. C. (2003). Heat transfer coefficients on the squealer tip and near squealer tip regions of a gas turbine blade. ASME Journal of Heat Transfer. 125 (4): 669-677. https://doi.org/10.1115/1.1571849.

Lee S. W. and Kim S. U. (2010). Tip gap height effects on the aerodynamic performance of a cavity squealer tip in a turbine cascade in comparison with plane tip results: Part 1 - tip gap flow structure. Experiments in Fluids. 49 (5): 1039-1051. https://doi.org/10.1007/s00348-010-0848-6.

Ma H., Wang Z., Wang L., Zhang Q., Yang Z., et al. (2016). Ramp heating in high-speed transient thermal measurement with reduced uncertainty. Journal of Propulsion and Power. 32 (5): 1190-1198. https://doi.org/10.2514/1.B35803.

Newton P. J., Krishnababu S. K., Lock G. D., Hodson H. P., Dawesand W. N., et al. (2006). Heat transfer and aerodynamics of turbine blade tips in a linear cascade. ASME Journal of Turbomachinery. 128 (2): 300-309. https://doi.org/ $10.1115 / 1.2137745$. 
O’Dowd D. O., Zhang Q., He L., Oldfield M. L. G., Ligraniand P. M., et al. (2011). Aero-thermal performance of a winglet at engine representative Mach and Reynolds numbers. ASME Journal of Turbomachinery. 133 (4): 041026. https://doi.org/ $10.1115 / 1.4003055$.

Palafox P., Oldfield M. L. G., Ireland P. T., Jones T. V., and LaGraff J. E. (2012). Blade tip heat transfer and aerodynamics in a large scale turbine cascade with moving endwall. ASME Journal of Turbomachinery. 134 (2): 021020. https://doi.org/ $10.1115 / 1.4003085$

Papa M., Goldstein R. J., and Gori F. (2003). Effects of tip geometry and tip clearance on the mass/heat transfer from a largescale gas turbine blade. ASME Journal of Turbomachinery. 125 (1): 90-96. https://doi.org/10.1115/1.1529190.

Rhee D. H. and Cho H. H. (2006). Local heat/mass transfer characteristics on a rotating blade with flat tip in a low-speed annular cascade - Part 2: tip and shroud. ASME Journal of Turbomachinery. 128 (1): 110-119. https://doi.org/10.1115/ 1.2098767

Saha A. K., Acharya S., Prakash C., and Bunker R. S. (2006). Blade tip leakage flow and heat transfer with pressure side winglet. International Journal of Rotating Machinery. 2006: 1-15. https://doi.org/10.1155/IJRM/2006/17079.

Schabowski Z., Hodson H., Giacche D., Power B., and Stokes M. R. (2014). Aeromechanical optimization of a wingletsquealer tip for an axial turbine. ASME Journal of Turbomachinery. 136 (7): 071004. https://doi.org/10.1115/1.4025687.

Tallman J. and Lakshminarayana B. (2001). Numerical simulation of tip leakage flows in axial flow turbines with emphasis on flow physics: Part II — effect of outer casing relative motion. ASME Journal of Turbomachinery. 123 (2): $324-333$. https://doi.org/10.1115/1.1369113.

Teng S., Han J. C., and Azad G. M. S. (2001). Detailed heat transfer coefficient distributions on a large-scale gas turbine blade tip. Journal of Heat Transfer. 123 (4): 803-809. https://doi.org/10.1115/1.1373655.

Yang D., Yu X., and Feng Z. (2010). Investigation of leakage flow and heat transfer in a gas turbine blade tip with emphasis on the effect of rotation. ASME Journal of Turbomachinery. 132 (4): 041010. https://doi.org/10.1115/1.3213560.

Yaras M. I. and Sjolander S. A. (1992). Effects of simulated rotation on tip leakage in a planar cascade of turbine blades: Part I — tip gap flow. ASME Journal of Turbomachinery. 114 (3): 652-659. https://doi.org/10.1115/1.2929190.

Zhong F., Zhou C., Ma H., and Zhang Q. (2017). Heat transfer of winglet tips in a transonic turbine cascade. Journal of Engineering for Gas Turbines and Power. 139 (1): 012605. https://doi.org/10.1115/1.4034208.

Zhou C. (2015). Effects of endwall motion on thermal performance of cavity tips with different squealer width and height. International Journal of Heat and Mass Transfer. 91: 1248-1258. https://doi.org/10.1016/j.ijheatmasstransfer.2015.07.101.

Zhou C., Hodson H., Tibbott I., and Stokes M. (2013). Effects of winglet geometry on the aerodynamic performance of tip leakage flow in a turbine cascade. ASME Journal of Turbomachinery. 135 (5): 051009. https://doi.org/10.1115/1.4007831.

Zhou C. and Zhong F. (2016). A novel suction side winglet design method for high pressure turbine rotor tips. ASME Paper No. GT2016-56218. https://doi.org/10.1115/GT2016-56218. 